\title{
Book Review: Learning and Teaching in Distance Education: Analyses and Interpretations from an International Perspective
}

\author{
P. Ramanujam \\ Indira Ghandi National Open University
}

Learning and Teaching in Distance Education: Analyses and Interpretations from an International Perspective

Otto Peters (2001)

London: Kogan Page

248 pp.

ISBN 0-7494-3594-1

\section{Reviewed by P.R. Ramanujam Indira Ghandi National Open University}

Theorising distance education (DE) had never been as challenging and tentative as it is today. If lack of firm theories of $\mathrm{DE}$ was the focal point of debates during the 1960s, 1970s and 1980s, the 1990s marked a proliferation of theories, mainly concerning technology-based delivery and market-driven curriculum. Perhaps there was too much theory of delivery, but too little of pedagogy in the somewhat lopsided and often superficial and repetitive reinforcement of the importance of learning and learner autonomy. With the uncritical emphasis on learner autonomy, teaching and pedagogy were nearly forgotten, despite a need to talk about it with some vigour and understanding. With DE practitioners' growing preoccupation with online courses, particularly with access to unlimited sources of information, there is a definite need to step out of the giant spinning wheel of a technology-driven DE race, relax for a while, and reflect on what is actually happening to learning and teaching. But very few have attempted such an exercise. In the age of online and web-based education that diverts so much attention to design and delivery issues, this new book by Otto Peters addresses some of the substantial issues of distance education pedagogy.

The simple and straightforward title of this book may give the impression that it is for light reading. However, a careful reader, suspecting the title reveals less and conceals more will be challenged to go beyond the surface details to discover the richer content, rarely found in the numerous publications in the field of distance education. Rooted in the humanistic tradition of Immanuel Kant, Otto Peters adopts an eclectic position in understanding and accommodating the fast changing technological revolution and its impact on teaching and learning at a distance. Inevitably, Peters chooses to comment on the danger of simplistic solutions offered by those technology enthusiasts who are oblivious 
Book Review: Learning and Teaching in Distance Education: Analyses and Interpretations from an International Perspective

to pedagogic and sociological consequences of online and web-based education. Though not radical, Peters' philosophical framework makes amply clear what both humanists and radicals should look for in DE today.

Wherever necessary in the book's eight chapters, Peters offers commentary on the arguments he advances. The physical layout of the chapters incorporates some features of self-instructional materials. The style is not conversational in the usual sense, and the tone is grave - suitable to serious academic discourse. However, for serious readers, a dialogue is effected between the reader and the text, the ideas, the arguments, the issues and challenges presented. This dialogue requires, besides exposure to distance/open learning in today's world, a degree of familiarity with philosophy, psychology, and history of education.

Chapter 1 takes stock of access, the growth of distance education through three generations, the dilemma regarding quantity verses quality, and characteristics of students. In chapter 2, Peters presents the salient features of various models of distance education, including the: (a) correspondence model; (b) conversation (two-way communication) model; (c) teacher model; (d) tutor model; and (e) technological extension model. Peters focuses on the changing nature of pedagogical issues. Chapter 3 is an exposition of three constitutive concepts of distance education - dialogue, structure and autonomy. The pedagogical, philosophical and sociological significance of these concepts are analysed indepth, and the debate is carried forward with more insights. Chapter 4 reviews the applications of these three concepts in various practices of distance education, including: (a) dialogue in counseling, tutoring, peer group interaction, and so forth; (b) pedagogic functions of the structural elements determined by behaviourism and educational technology; and (c) autonomous learning and its limits in the current practices of distance education. In Chapter 5, Peters discusses how the concepts of open learning, lifelong learning, industrialised learning and teaching, and postmodern learning modify dialogue, structure and autonomy. Chapter 6 explores how digital information and communication can help distance education achieve goals in mass education, democratisation; and quality learning, as well as meet new requirements for teaching or learning through the new technologies. In chapter 7, Peters critically reviews the practices of some of the leading distance teaching universities, including:

- University of South Africa;

- Open University (UK);

- FernUniversitat (Germany);

- Central Radio and Television University (China);

- University of Air (Japan);

- Empire-State College (USA);

International Review of Research in Open and Distance Learning 
Book Review: Learning and Teaching in Distance Education: Analyses and Interpretations from an International Perspective

- American National University Teleconference Network; and

- the Canadian project "Contact-North'.

Chapter 8 summarizes the analyses and perspectives of the preceding seven chapters. The brief appendix that follows chapter 8 lists the various "stations on the road from written to digitized teaching text" (Peters, 2001, p. 247).

If the recurring themes of the book are dialogue, structure and autonomy, the contexts are preindustrial, industrialised and the postindustrial situations of distance teaching and learning. Peters also discusses the related issues of advanced technology, and distance education pedagogy vis-à-vis pedagogics of adult learning and classroom teaching. The range of issues and their interconnections are impressive, and Peters' treatment of the issues is refreshing.

While analysing the importance of the pedagogical, philosophical, anthropological and sociological aspects of dialogue, Peters argues for the provision of opportunities to acquire education through knowledge, mediated through dialogue; without these, genuine scientific thinking cannot develop. One realizes that in the distance teaching-learning context, dialogue is a must, not only between the student and the teacher but also among the teachers themselves. The implications of Peters' views are significant in the contexts of strong oral traditions and the painful transitions of teaching/learning from expository, prescribed teaching traditions to exploratory self-learning practices, often without prior experiences or knowledge about existing models. This is particularly true in developing countries that have not developed models of their own.

Peters recognises the limits of educational technology structures when they confront the notion of autonomy, but emphasises the advantages that these structures provide in effecting mass education programmes. While mass education necessarily retains the structured (somewhat closed) pedagogics, those who call for open, autonomy in learning urge more participation and self-initiative by learners which requires removal of structures, both institutional and pedagogical, which restrict learner autonomy in the real sense. The next logical step, therefore, is to change the restricting structures and allow more student autonomy. The key to this 'Copernican revolution' is interactive communication technology. Can sophisticated technology alone bring about the revolution? There are no easy answers.

Peters equates the correspondence, distance and digital models as parts of the preindustrial, industrial, and postindustrial stages of distance education. He attempts to establish the necessary links between these stages of distance education evolution with social evolution, as such. While doing so, he introduces the fordist and postfordist approaches to production technologies, and convincingly argues how in fordist (and modernist) and postfordist (i.e., postmodern) societies, these approaches will lose their significance. If the industrialist society was satisfied with mass production of standardised products (e.g., selling 15

International Review of Research in Open and Distance Learning 
Book Review: Learning and Teaching in Distance Education: Analyses and Interpretations from an International Perspective

million Ford cars), the postindustrial society demands variety to satisfy individual tastes. The parallels in distance education are in the mass education of the 1960s allowing relatively more autonomy to the learners. The reference point, however, has long remained face-to-face classroom teaching. This is problematic. Peters criticizes the "one dimensionality" (p. 40) of the communication in distance education that precludes socialisation. It is precisely this socialisation through peer group interaction and teacher-student dialogue that is promised by the digital information and communication made abundantly available by modern technology - the satellite, the computer and telecommunication. Peters expects students to change their learning methods as much as teachers will have to change their methods of presentation. He notes the major failure of technology-based distance education is its inability to fully exploit the potential of media to make distance education open. Citing Anthony Bates, Peters shows how only "the cheapest medium, the audio cassette, has been able to make any sort of a career in the Open University, which is very open-minded with regard to media for pedagogics and is an international pioneer and trendsetter" (Peters, 2001, p. 130). Assessing the possibilities of open lifelong and continuing education in the postindustrial (postfordist, postmodern) era, Peters sees a bright future for distance education, provided technological facilities are creatively and imaginatively blended to evolve a new pedagogy rather than replicating conventional face-to-face classroom teaching/learning practices. In the context of teleconferencing, Peters draws a clear line between the North American view of using technology to increase the access to traditional university teaching, and the European interest "in the pedagogical processing and optimizing of teaching with the help of technical media, whereby they deliberately remove themselves from traditional forms of academic teaching" (Peters, 2001, p.144). While recognising the need for different models of distance education operating in the different "real academic and social conditions" (p. 145), Peters, however, cautions:

no one has anything to say against the practice of teleconferencing at North American universities; what we must defend ourselves against, however, is the claim that a pattern has been developed...that reduces to nothing the previous pedagogical development of distance education and declares it to be unnecessary because it is no longer required as the distance education of the future must be developed on the basis of the new paradigm. We must object to this (p. 145.).

This caution is extremely significant, coming as it does from the European thinker whose definition of distance education in the 1960s as the industrialised form of education is still the first commandment for many in developing countries. This caution holds well in objecting to the perceived success models which ignore specific socio-cultural realities and which warrant different forms and practices of distance education, particularly when it is fast sliding into a digital mode.

International Review of Research in Open and Distance Learning 
Book Review: Learning and Teaching in Distance Education: Analyses and Interpretations from an International Perspective

The uncritical replication of the OU(UK) model in many Asian and African countries has already taken its toll. If the American model of teleconferencing is also replicated, then, the dream of distance education as a force for democratising education to all may turn into a nightmare. This applies to online models too. The powerful technology lobbies, modernising distance education through the latest communication technology, give only a partial response when they encounter institutions with inadequate infrastructure back up and limited trained human power to use it appropriately. Piecemeal utilisation of information and communication technologies, for example, creates more problems than it solves, and the high cost involved is often unjustified in poor countries.

Peters candidly admits the demanding nature of digital media and the predictable resistance from the teachers who are not prepared to work through multimedia. Though the media in distance education theoretically offers a large number of pedagogical structures, in practice institutions develop inflexible models. But Peters emphasizes again and again the inevitable move towards the digital information age. At the same time, both the quality of information and the purpose of dialogue are seen as the prerequisites of genuine distance education practice. Analysing the different models of distance education in South Africa, the UK, Germany, the United States, Canada, Japan and China, Peters argues strongly in favour of having different models rooted in different social, cultural and academic traditions. He disapproves of artificial impositions and unreasonable modernising proposals. His commentary on the University of South Africa is an example of a balanced assessment of the contributions of various models of distance education. However, he is firm in his belief that digital, information-based distance education points towards "the future of an information and learning society in which its concepts and experience will be more important than they are today" (p. 246).

Some of the crucial arguments and insights presented in this book need to be revisited. Some of the antinomies present in the sub-text include:

- academic socialisation and autonomous learning;

- advantages of structured self-instructional courses and the need for open learning;

- the need to deviate from traditional classroom teaching and the yearning for academic recognition by traditional institutions;

- the potential of new media, and the reluctance or resistance of teachers to change their set patterns of presentations within distance teaching institutions;

- mass continuing education programmes; and

- the need for high quality research.

International Review of Research in Open and Distance Learning 
Book Review: Learning and Teaching in Distance Education: Analyses and Interpretations from an International Perspective

While arguing for the one, we notice how the other emerges as the countervailing force. If the co-existence of the above arguments is possible and acceptable, then, a different kind of theoretical framework and more flexible pedagogics will have to be imagined. Peters' own eclectic position does not allow him to go for a more sustained criticism that is necessary to see the concrete features of such a framework.

Pedagogically speaking, should we treat classroom teaching as traditional and by implication an antithesis to distance education? Do not digital information and multimedia alter classroom teaching as much as they do in the case of distance education? Does the adjective traditional connote, besides the mode, the nature of the educational content transacted in the classroom? With the convergence of face-to-face and distance modes increasing, should we still emphasise only the distinction between the two? If multimedia makes it possible and cheaper, is it wrong to replicate or even imitate a good classroom experience? While arguing for autonomous learning in the postmodern, postindustrial, postfordist era, are we not unwittingly legitimising the extremely individualistic, asocial, fragmented and anarchic trends typical of later day ('postmodern', if you like) imperialist ideologies? Should education reflect and endorse only the ruling ideas of the ruling classes through dominant technologies?

The additions made to chapter 6 in the paperback edition (sub-section 6.7) are important in the context of the above questions. The pedagogical flexibility of the virtual university has been analysed in detail. In the final analysis, discussions of flexibility are judged by accessibility, choice and control by students, students' responsibility and the support that the students would need. It is interesting to note the order in which the issues are listed. Students in developing countries usually stop with the first issue itself, accessibility. Assuming that access, choice, support, and so forth are provided for, the question of students' responsibility remains. What kind of responsibility? This is the key question that begs the answer. Peters says "in order to understand the meaning of virtual learning it must be noted that the learning process itself is never virtual, but always quite real" (Peters, 2001, p. 157.).

This is an extremely important observation, since the virtual spaces through which the learner learns are, according to Peters, boundless, uncertain, inconceivable and empty. The challenge here for the learner is to acquire real learning through virtual environments. Viewed this way, the responsibility of the learner as well as the teacher is daunting. Flexibility, in all its range and variety, also must be meaningfully related to: (a) effective learning strategies; (b) quality of content; and (c) the necessary pedagogic support of mentoring, counselling and peer group interaction.

Peters' detailed analysis of the concepts related to autonomous, self-directed learning and the three types of Internet-based universities (ThinkPad universities, Internet universities, and virtual universities) suggests that the learner as well as society are provided with unlimited sources of knowledge and are also

International Review of Research in Open and Distance Learning 
Book Review: Learning and Teaching in Distance Education: Analyses and Interpretations from an International Perspective

faced with unpredictable consequences and risks. Attainment of self-directed learning, as described by Malcolm Knowles' (p. 163) is possible, provided the learner has all those attributers of Knowles' adult learner. The anticipated pedagogical goal also raises a number of sociological and psychological issues:

1. How will the necessary learning environments be created in a democratic way with a humanistic approach, when the whole range of innovations technological or otherwise - are purely market driven with profit motive?

2. Who will decide on the kind of Internet-based experiences that the learner should have or will have, at what stage and at what cost?

3. Can dialogue, autonomy and structure be meaningful without the presence - not the physical one - of good teachers (by whatever name they are called) who create a new body of knowledge before it is put on the Internet or the WWW?

4. Will not the self-directed learning of the present kind further alienate the learner from the real world which is already much alienated, fragmented and dehumanised?

The above and many more such questions will have to be asked in the context of our lived and living reality in order to control and choose the right kind of learning, strategies. The constructivist approach can help us, only to the extent that we construct the world we know. Here, the Kantian categories are persuaded to pass through Hegelian dialectics, anticipating Marxian reversal of both. References to Piaget are certainly not a resolution of the conflicts but an attempt to search for multiple solutions to a problem posed by a unipolar world covered by different layers of ideological veils - not necessarily the outgrowth of German ideology alone. Peters' search would continue, though the discoveries may be startling to all of us. Undoubtedly, this book will become a classic in the educational debate of technology versus pedagogy.

Citation Format

Ramanujam, P. (July, 2001) Book Review: Learning and Teaching in Distance Education: Analyses and Interpretations from an International Perspective. International Review of Research in Open and Distance Learning: 2, 1. http://www.icaap.org/iuicode?149.2.1.10 